\title{
Posttranslational Modification of Neurofilament Proteins by Phosphate During Axoplasmic Transport in Retinal Ganglion Cell Neurons
}

\author{
Ralph A. Nixon, Susan E. Lewis, and Charles A. Marotta \\ Ralph Lowell Laboratories and Molecular Neurobiology Laboratory of the Laboratories for Psychiatric Research, Mailman \\ Research Center, McLean Hospital, Belmont, Massachusetts 02178; and Department of Psychiatry and Program in \\ Neuroscience, Harvard Medical School, Boston, Massachusetts 02115
}

The progressive modification of newly synthesized neurofilament proteins (NFPs) during axoplasmic transport in mouse retinal ganglion cell (RGC) neurons was studied after RGC perikarya were pulse-labeled with ${ }^{32}$ P-orthophosphate or radiolabeled amino acids. The 3 NFP subunits, H(igh), $M$ (iddle), and L(ow), were among a group of axonally transported proteins that incorporated high levels of ${ }^{32} \mathrm{P}$. Covalent addition of phosphate slowed the electrophoretic mobility of $H$ and $M$ on SDS polyacrylamide gels and shifted the charge of all 3 subunits toward more acidic pH values, thereby providing an index of the phosphorylation state of this radiolabeled population of NFPs. NFPs were extensively phosphorylated before they entered axons at the optic nerve level, and continued to be modified during transport along RGC axons at the optic nerve and tract level. $H$ and $M$ exhibited charge shifts of 0.2-0.6 units toward a more acidic pH during axoplasmic transport. The charge modifications became more prominent when NFPs reached distal axonal levels, which may indicate regional differences in the activity of this modification process along axons. By contrast, the $L$ subunit became more basic in charge, conslstent with decreases in the phosphorylation state during transport. Additional observations (Nixon and Lewis, 1986) that a considerable proportion of phosphate groups initially added to $L$ and $M$ were later removed as neurofilaments advanced along RGC axons support the notion that the changing phosphorylation state of NFP subunits during axoplasmic transport reflects a dynamic equilibrium between phosphorylation and dephosphorylation events. Topographical remodeling of phosphate groups on NFPs during axoplasmic transport is proposed as a possible mechanism for coordinating interactions between neurofilaments and other constituents, as these elements are transported and integrated into the axonal cytoskeleton.

The cytoskeletons of most higher eukaryotic cells contain a network of 100-110 $\AA$ filaments, which are thought to influence

\footnotetext{
Received June 4, 1986; revised Sept. 8, 1986; accepted Oct. 2, 1986.

These studies were supported by grants from the U.S. Public Health Service (AG 02126, AG 05604, AG 04522 and NS 17535), the Anna and Seymour Gitenstein Foundation, the McKnight Foundation, and the American Health Assistance Foundation.

Correspondence should be addressed to Ralph A. Nixon, Ralph Lowell Laboratories, McLean Hospital, Belmont, MA 02178.

Copyright (C) 1987 Society for Neuroscience 0270-6474/87/041145-14\$02.00/0
}

changes in cell shape (Morris and Lasek, 1982; Hirokawa et al., 1984; Hoffman et al., 1984; Lasek et al., 1984) and to serve as a scaffold to organize other cellular constituents into functional arrays within the cytoplasm (Lazarides, 1980; Steinert et al., 1984; Jones et al., 1985). Intermediate filaments are encoded by a large multigene family, the members of which are differentially expressed in different tissues (Fuchs and Hanukoglu, 1983). Five major classes of intermediate filaments have been defined by biochemical and immunological criteria (Lazarides, 1980), including keratin filaments of epithelial origin, desmin filaments in muscle cells, vimentin filaments of mesenchymalderived cells, glial filaments in certain glial cell types, and neurofilaments in many differentiated neurons.

Neurofilaments in most vertebrate species are composed of 3 subunits (Shelanski and Liem, 1979) - L (low), M (middle), and $\mathrm{H}$ (high)-denoting, respectively, a 68-70 kDa central "core" (Geisler and Weber, 1981; Willard and Simon, 1981; Liem and Hutchison, 1982) and 2 subunits of $110-160$ and $160-210 \mathrm{kDa}$ that are more peripherally situated within the neurofilament (Willard and Simon, 1981; Sharp et al., 1982; Hirokawa et al., 1984; Marotta, 1984). Despite their different molecular weights, the NFP subunits share important structural features in common with other intermediate filament subunits (Geisler et al., 1983; Weber et al., 1983), including a highly conserved central domain, approximately 300 amino acid residues in length, flanked by hypervariable non- $\alpha$-helical end-domains of variable size and sequence (Fuchs and Hanukoglu, 1983; Steinert et al., 1985). These end-domains are predominantly represented on the surface of the assembled filament and may specify functions unique to a particular subunit or intermediate filament subclass (Weber et al., 1983; Steinert et al., 1985).

In addition to their similarities in peptide structure, intermediate filaments of various subclasses are modified after synthesis by addition of phosphate groups to the polypeptide backbone, which suggests that phosphorylation may play a fundamental role in intermediate filament function. The $\mathrm{L}$ subunit of neurofilaments, like the subunits of desmin (O'Connor et al., 1981) and vimentin (Steinert et al., 1982) filaments, has 1 or several phosphorylated sites (Jones and Williams, 1982; Julien and Mushynski, 1982; Shecket and Lasek, 1982; Carden et al., 1985). The $\mathrm{M}$ and $\mathrm{H}$ subunits, however, are extensively phosphorylated, containing as many as 9-24 and 22-100 phosphate groups per molecule, respectively (Jones and Williams, 1982; Julien and Mushynski, 1982; Wong et al., 1984; Carden et al., 1985). The phosphate groups are located predominantly 


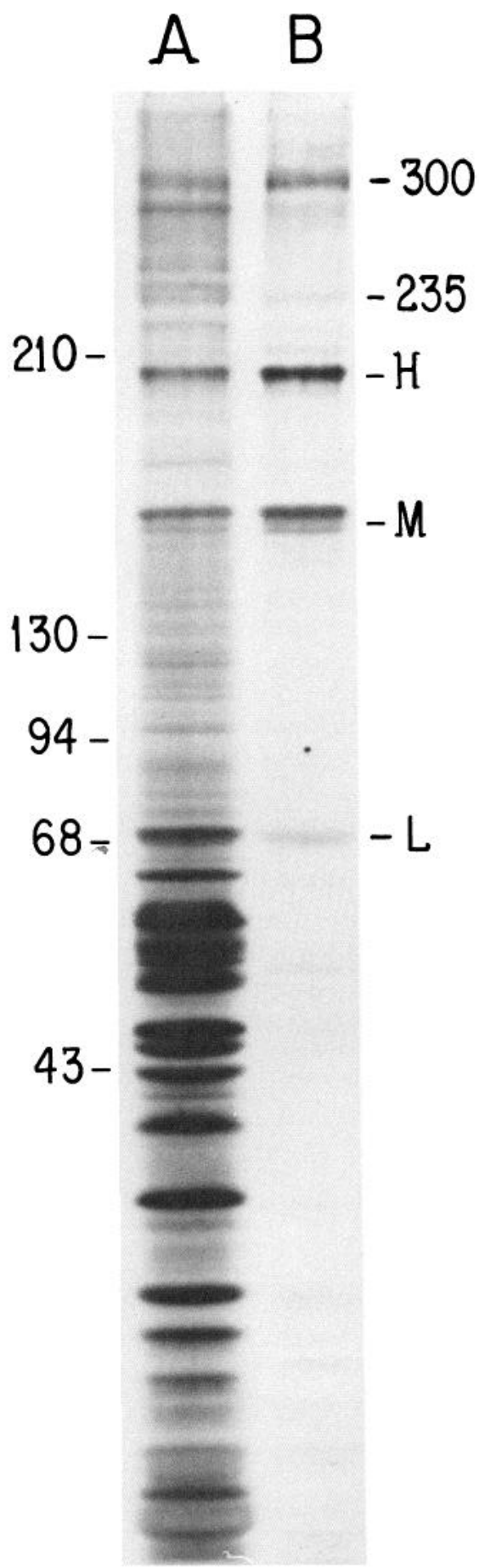

Figure 1. One-dimensional SDS-PAGE analysis of ${ }^{3} \mathrm{H}$-proline- and ${ }^{32} \mathrm{P}$-orthophosphate-labeled proteins comprising the slow phases of axoplasmic transport in RGC axons. Optic pathways were obtained $6 \mathrm{~d}$ after mice were injected intravitreally with ${ }^{3} \mathrm{H}$-proline (lane $A$ ) or ${ }^{32} \mathrm{P}$ orthophosphate (lane $B$ ). Proteins in these samples were separated by 1-dimensional SDS-PAGE on gels containing a 3-7\% acrylamide gradient. After electrophoresis, radiolabeled proteins were visualized by fluorography. The positions of the NFP subunits $H, M$, and $L$ are indicated.

on the carboxyterminal end-domain of the neurofilaments (Julien et al., 1983; Carden et al., 1985; Geisler et al., 1985a). In the case of the $\mathrm{H}$ subunit, this region of the polypeptide appears to contribute to the cross-bridges between axonal neurofilaments
(Willard and Simon, 1981; Sharp et al., 1982; Hirokawa et al., 1984). These observations raise the possibility that phosphorylation may not only regulate aspects of neurofilament assembly but also certain interactions between neurofilaments and other neuronal constituents.

Neurofilaments in most neurons are continually synthesized and transported along axons (Hoffman and Lasek, 1975; Black and Lasek, 1980; Willard, 1983). In some neurons, transported neurofilaments leave the moving phase and become integrated into a stationary axonal cytoskeletal network (Nixon, 1983; Nixon and Logvinenko, 1986) that is regionally specialized along axons (Brown et al., 1982; Nixon et al., 1982). The translocation of neurofilaments and the extensive reorganization processes within the axon suggest, therefore, that interactions of neurofilaments with other cytoskeletal proteins and with membranous organelles may be highly dynamic and tightly regulated. If phosphorylation were a regulatory step in mediating such interactions, it might be expected that phosphate groups would be added and possibly turned over with a characteristic timing and location dependence within the neuron. Consistent with this notion are recent biochemical observations that suggest that phosphorylation of NFPs may be topographically segregated within some neurons (Bennett and DiLullo, 1985; Pant et al., 1986). These findings extend earlier immunocytochemical studies that demonstrated selective immunostaining of most neuronal cell bodies by antibodies recognizing unphosphorylated epitopes of $\mathrm{H}$, and predominantly axonal staining by antibodies against phosphorylated epitopes on this subunit (Sternberger and Sternberger, 1983). Interestingly, the normal segregation of highly phosphorylated neurofilaments in axons revealed by these antibodies seems to be partially disrupted in some neurons in pathological states associated with perikaryal accumulation of neurofilaments (Cork et al., 1986; Troncoso et al., 1986).

In the present study, we examined the progressive modification of newly synthesized NFPs in mouse retinal ganglion cell (RGC) neurons after pulse-labeling RGC perikarya in vivo with ${ }^{32} \mathrm{P}$-orthophosphate or radiolabeled amino acids. We have focused on the intermediate stages in the modification process that take place during axoplasmic transport along RGC axons in an effort to clarify the spatiotemporal relationship between NFP phosphorylation and the reorganization of the neurofilament network that exists during axoplasmic transport (Nixon and Logvinenko, 1986; Nixon, 1987). Together with studies of phosphate turnover on NFP during axoplasmic transport (Nixon and Lewis, 1986) and on modification events that precede the appearance of NFPs in the optic nerve (Nixon et al., 1986), our results indicate that the phosphorylation state of each NFP subunit is regulated by a dynamic balance between phosphorylation and dephosphorylation. These processes are modulated differently in various sites within the neuron.

\section{Materials and Methods}

Isotope injections. Radiolabeled compounds were injected intravitreally into anesthetized male and female C57BL/6J mice, aged 10-14 weeks, with a calibrated micropipette apparatus. Mice received $0.20 \mu \mathrm{l}$ of PBS, pH 7.4, which contained $15-25 \mu \mathrm{Ci}$ of $\mathrm{L}-2,3-{ }^{3} \mathrm{H}$-proline (sp act, $30-50$ $\mathrm{Ci} / \mathrm{mmol}$ ), $50-100 \mu \mathrm{Ci}$ of $\mathrm{L}^{35} \mathrm{~S}$-methionine (sp act, $400 \mathrm{Ci} / \mathrm{mmol}$ ), or 50-100 $\mu \mathrm{Ci}$ of ${ }^{32} \mathrm{P}$-orthophosphate (sp act, $1000 \mathrm{Ci} / \mathrm{mmol}$ ), purchased from New England Nuclear (Boston, MA).

Tissue preparation. Mice were killed by cervical dislocation followed by decapitation. After the brain was cooled, the optic nerve and tract were freed from meninges and the optic tract on each side was severed at a point $2.5 \mathrm{~mm}$ from the superior colliculus. This dissected length 
of primary optic pathway was $9 \mathrm{~mm}$ long and consisted of the optic nerves severed at the scleral surface of the eye, the optic chiasm, and lengths of the optic tract extending to, but not including, terminals in the lateral geniculate nucleus. The optic pathway was cut at the level of the midpoint of the optic chiasm to yield an optic nerve and an optic tract sample; in other experiments, the optic pathway was cut into consecutive $1.1 \mathrm{~mm}$ segments on a micrometer-calibrated slide. All manipulations were performed at $0^{\circ} \mathrm{C}$ or with the tissue in the frozen state.

Polyacrylamide gel electrophoresis. One-dimensional SDS-PAGE was carried out on $320 \mathrm{~mm}$ slab gels using 3-7\% or 5-15\% linear polyacrylamide gradients (Nixon et al., 1983). Two-dimensional polyacrylamide gels containing SDS were prepared as previously described, using an 8$18 \%$ polyacrylamide gradient (Brown et al., 1981).

Identification of radioactive proteins. On gels stained with Coomassie brilliant blue, NFPs were identified by comparing their migration relative to that of cytoskeletal proteins isolated by the method of axonal flotation. ${ }^{3} \mathrm{H}$-proline-labeled proteins on Coomassie-stained gels were detected by fluorography (Marotta et al., 1979). Proteins labeled with ${ }^{32} \mathrm{P}$-orthophosphate or ${ }^{35} \mathrm{~S}$-methionine were detected by autoradiography. Pairs of autoradiograms of gels from the same first-dimension run were compared by aligning the positions of reproducibly observable markers that were visible on the corresponding Coomassie blue-stained gels (see Fig. 2D).

Isolation of NFPS. A protein fraction enriched in neurofilaments was prepared from mouse CNS white matter by axonal flotation (Liem et al., 1978) with modifications (Brown et al., 1981). In experiments involving alkaline phosphatase digestion, cytoskeletal protein fractions were prepared by the method of Chiu and Norton (1982) from mouse optic pathways.

Alkaline phosphatase digestion of unlabeled and ${ }^{32} P$-labeled NFPs. Cytoskeletal protein fractions were incubated with $E$. coli alkaline phosphatase (Sigma) $\left(1 \mathrm{U} / \mathrm{mg}\right.$ cytoskeletal protein) at $37^{\circ} \mathrm{C}$ for various intervals up to $18 \mathrm{hr}$ using the incubating conditions of Carden et al. (1985). In experiments involving ${ }^{32} \mathbf{P}$-labeled cytoskeletal proteins, the digested samples were subjected to electrophoresis on 3-7\% polyacrylamide gels. The bands corresponding to the neurofilament proteins were cut directly from gels that had been stained with Coomassie blue, and were then counted in a Beckman LS 7000 liquid-scintillation counter. ${ }^{32} \mathrm{P} \mathrm{dpm}$ were adjusted for isotopic decay. In addition, the value for each radioactive protein was corrected for background radioactivity in each gel lane, since preliminary studies showed that, even for gel areas without discrete radiolabeled bands, a low level of radioactivity, proportional to the total radioactivity of proteins loaded onto the gel, was present. The appropriate background radioactivity, calculated from the total protein radioactivity loaded and the area of the gel slice containing the radiolabeled protein band, was subtracted. This background was 8$15 \%$ of the total ${ }^{32} \mathrm{P}$ radioactivity in the protein.

\section{Results}

\section{Radiolabeling of neurofilament proteins in $R G C$ neurons in}

vivo

Neurofilaments in mouse RGC neurons are composed of proteins with apparent molecular weights of $200(\mathrm{H}), 140(\mathrm{M})$, and $70 \mathrm{kDa}(\mathrm{L}$ ) (Fig. 1). $\mathrm{H}$ and $\mathrm{M}$ can each be resolved into at least 3 distinct species, with molecular masses of 195-205 and 140$145 \mathrm{kDa}$, respectively (Nixon et al., 1982; Lewis and Nixon, 1985); however, in the present study the microheterogeneous forms of each subunit are considered as 1 protein.

When mice were injected intravitreally with ${ }^{3} \mathrm{H}$-proline or ${ }^{35} \mathrm{~S}$-methionine, radiolabeled NFPs, previously identified by various biochemical criteria (Brown et al., 1981; Nixon et al., 1982), appeared in RGC axons by $1 \mathrm{~d}$ (Fig. $1 A$ ). About 40 other radiolabeled proteins composing the group IV and V (SCa and $\mathrm{SCb}$ ) phases of axoplasmic transport (R. A. Nixon, unpublished observations) were also present in axons from 1 to $14 \mathrm{~d}$ after injection. By contrast, after intravitreal injection of ${ }^{32} \mathbf{P}$-orthophosphate, few proteins in RGC axons were radiolabeled to a significant extent (Fig. $1 B$ ). Three proteins were identified as the neurofilament triplet proteins by the following criteria: their characteristic molecular weights (Fig. $1 B$ ), their exclusive presence in Triton-insoluble preparations of cytoskeletal proteins (Nixon and Lewis, 1986), and their migration on 2-dimensional polyacrylamide gels to the same position as unlabeled NFP subunits (Fig. 2). Also seen on the gel of Figure $1 B$ are a 235 $\mathrm{kDa}$ protein previously identified as the $\beta$-subunit of fodrin (Nixon, 1986) and an unidentified protein with an approximate molecular mass of $300 \mathrm{kDa}$.

\section{Axoplasmic transport of radiolabeled NFPs}

Studies were carried out to establish the site or sites within neurons at which NFPs become phosphorylated. Since phosphorylation is a posttranslational event, the rate of anterograde movement of ${ }^{32} \mathrm{P}$ associated with NFPs might reflect the axonal transport of NFPs that were labeled with ${ }^{32} \mathrm{P}$ in $\mathrm{RGC}$ perikarya or, alternatively, the axonal transport of a carrier of ${ }^{32} \mathrm{P}$ capable of transferring phosphate groups to NFPs in cell bodies or axons. In the latter case, the translocation rate of NFPs labeled via a ${ }^{32} \mathrm{P}$ carrier would therefore appear to be different from the group $\mathrm{V}$ rate of transport previously described for ${ }^{3} \mathrm{H}$ NFPs (Black and Lasek, 1980). Thus, to distinguish between these 2 possibilities, we compared the relative rates of movement of the ${ }^{32} \mathrm{P}$ label and the ${ }^{3} \mathrm{H}$ label associated with NFPs.

The distribution profiles of radiolabeled NFPs in 8 consecutive $1.1 \mathrm{~mm}$ segments of the optic nerve and optic tract were analyzed by electrophoresis at various intervals after injecting mice with radiolabeled proline or orthophosphate. During the interval of 3-15 d after injection, NFP subunits labeled with ${ }^{3} \mathrm{H}$-proline advanced in a constant stoichiometric relationship along RGC axons (Fig. 3; Nixon and Logvinenko, 1986). A rate of $0.5-0.6 \mathrm{~mm} / \mathrm{d}$ has previously been calculated from the progressive movements of the leading edge of the radiolabeled wave (Nixon et al., 1982). The movement of ${ }^{32} \mathrm{P}$-labeled neurofilament protein subunits appeared to be coordinate, as judged by the distribution profiles of each subunit along axons at different postinjection time points (Fig. 4). When contrasted with the ${ }^{3} \mathrm{H}$ NFPs, however, the ${ }^{32} \mathrm{P}$-phosphate groups associated with NFPs exhibited a different distribution pattern over time. Although barely detectable in axons by $3 \mathrm{hr}$ after injection, the level of ${ }^{32} \mathrm{P}$ radioactivity associated with NFPs was high in proximal axons by day 1-3 (Fig. 4). The minimal labeling of NFPs within distal axons at $3 \mathrm{hr}$ postinjection indicated that incorporation of blood-borne label was negligible. Diffusion of ${ }^{32} \mathrm{P}$ along optic glial cells after intravitreal injection also did not account for NFP labeling, since excised optic pathways did not incorporate ${ }^{32} \mathrm{P}_{\mathrm{i}}$ into NFPs in vitro, even though various glial cell proteins were labeled (Nixon, 1986). ${ }^{32}$ P-labeled NFPs were observed at progressively more distal axonal sites and reached the distal optic tract, $9 \mathrm{~mm}$ from the cyc, by day 5 after injection (Fig. 4). Therefore, at least some ${ }^{32} \mathrm{P}$-phosphate groups that became associated with neurofilament proteins advanced along RGC axons as rapidly as $1.8 \mathrm{~mm} / \mathrm{d}$. This rate, which is faster than the group V ( $\mathrm{SCa}$ ) phase of axoplasmic transport, suggested the presence of a transported carrier of ${ }^{32} \mathrm{P}$ phosphate groups. The persistence of ${ }^{32} \mathrm{P}$-labeled NFPs along RGC axons by day 20 , however, was consistent with the transport of some NFPs at a group V rate.

\section{Charge modification of NFPs during axoplasmic transport}

To determine whether or not NFPs become modified during translocation, we made use of the observation that phosphate 


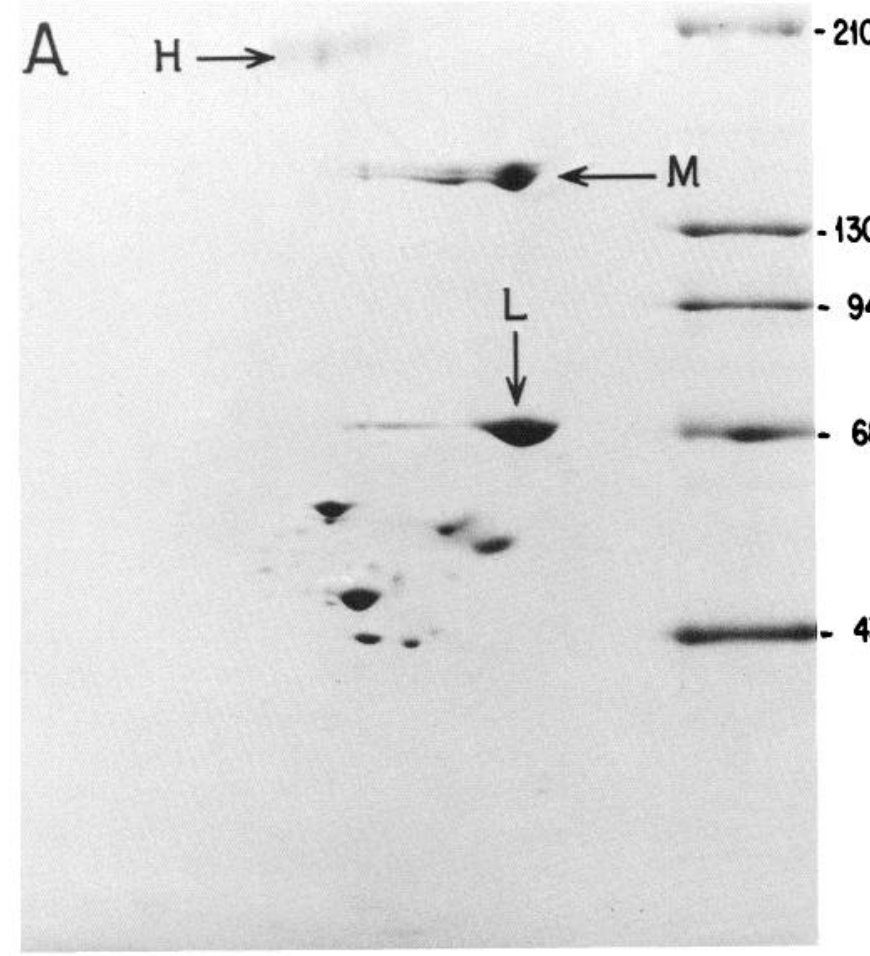

B $\rightarrow$
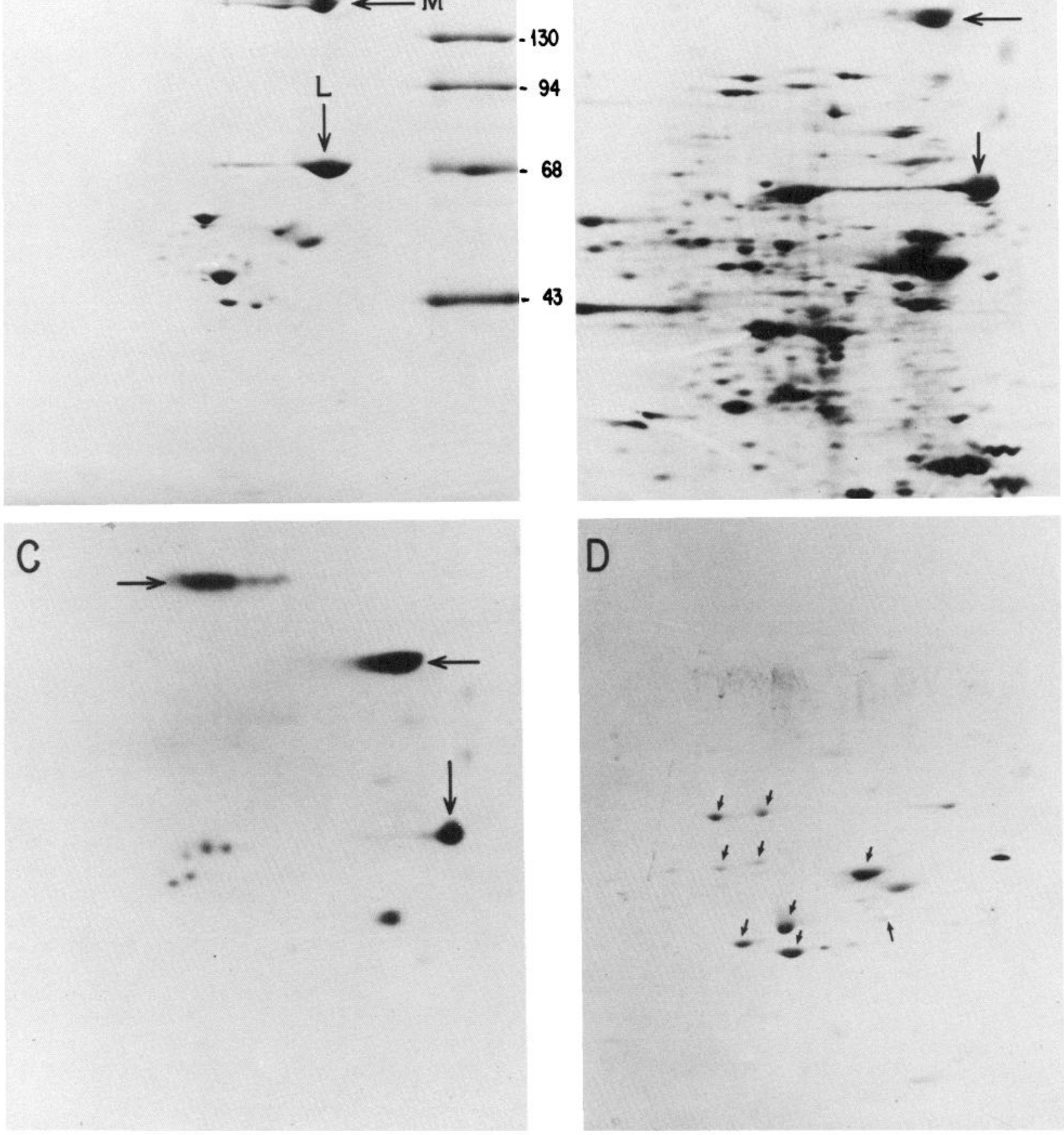

Figure 2. Two-dimensinal SDS-PAGE analysis of ${ }^{35} \mathrm{~S}$-methionine- and ${ }^{32} \mathrm{P}$-orthophosphate-labeled proteins composing the slow phase of axoplasmic transport in RGC axons. $A$, Positions of $H, M$, and $L$ in neurofilament-enriched fractions of mouse CNS white matter, prepared by the method of axonal flotation (Liem et al., 1978; Brown et al., 1981). Molecular weight standards, indicated on the right side, include myosin (210 $\mathrm{kDa}), \beta$-galactosidase $(130 \mathrm{kDa})$, phosphorylase B $(94 \mathrm{kDa}), \mathrm{BSA}(68 \mathrm{kDa})$ and ovalbumin $(43 \mathrm{kDa}) . B$, Radiolabeled proteins from optic pathways obtained from mice $6 \mathrm{~d}$ after intravitreal injection of ${ }^{35} \mathrm{~S}$-methionine. $C$, Radiolabeled proteins present in the optic pathway in mice $3 \mathrm{~d}$ after intravitreal injection of ${ }^{32} \mathrm{P}$-orthophosphate. Proteins in these samples were separated by 2-dimensional SDS-PAGE on gels containing an 8-18\% acrylamide gradient. The positions of the $H, M$, and $L$ are indicated by arrows. In all figures the basic end of the gel is on the left. $D$, Proteins of the mouse optic pathway stained with Coomassie brilliant blue. Proteins indicated by arrows were used as standard position markers to align the pairs of autoradiographs in Figures 5 and 6, and to verify that shifts in the isoelectric points of ${ }^{32}$ P-labeled NFPs were not due to gel electrophoresis artifact. 

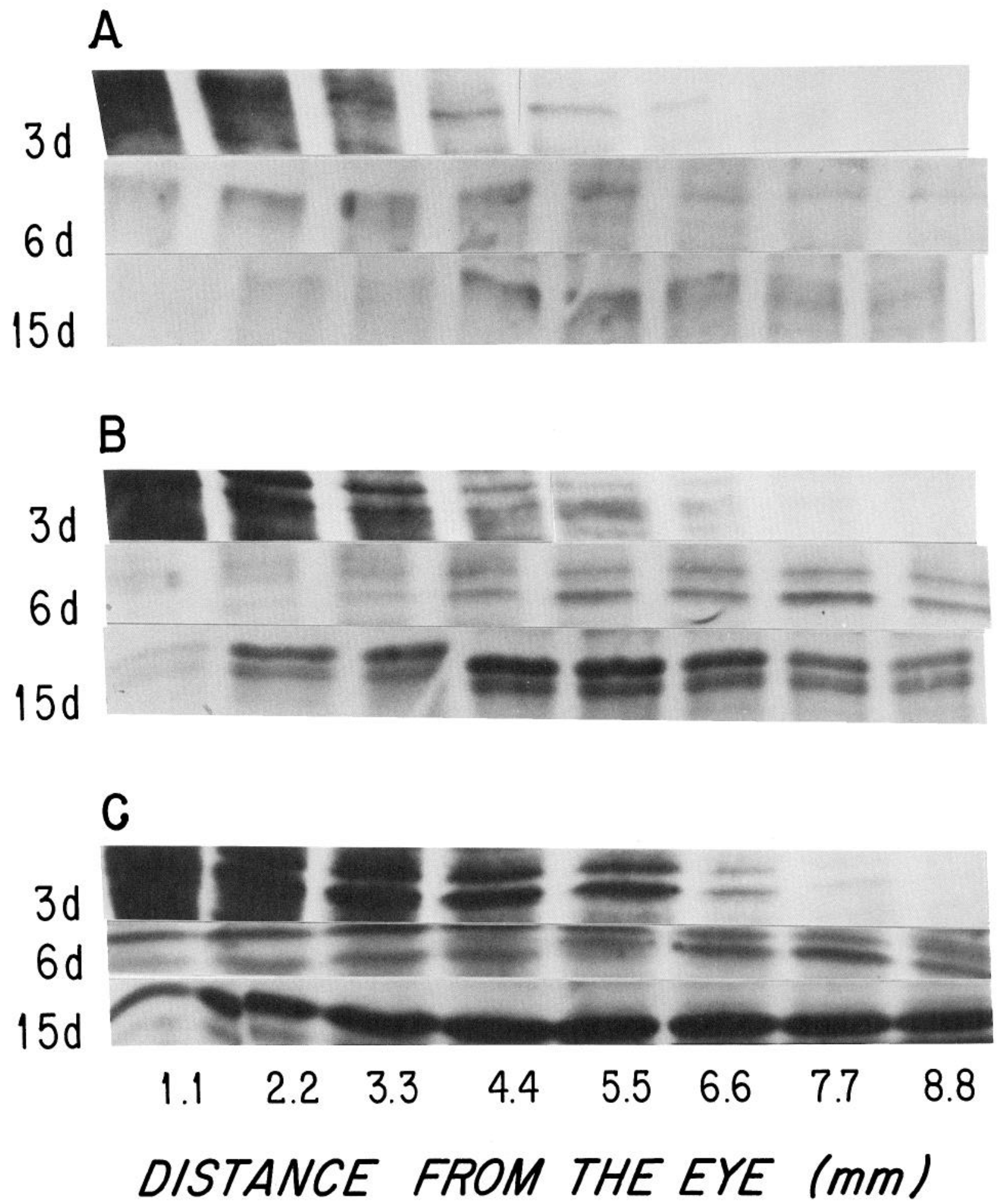

Figure 3. Distribution of newly synthesized NFPs along RGC axons at different intervals after intravitreal injection of ${ }^{3} \mathrm{H}$-proline. Optic pathways from mice 3,6, and $15 \mathrm{~d}$ after ${ }^{3} \mathrm{H}$-proline injection were cut into 8 consecutive $1.1 \mathrm{~mm}$ segments. Each segment was subjected to SDS-PAGE on a 3-7\% linear polyacrylamide gradient, and after staining gels with Coomassie blue, radioactivity in the protein bands was visualized by fluorography. The gel regions corresponding to the positions of $\mathrm{H}$ (panel $A$ ), $\mathrm{M}$ (panel $B$ ), and $\mathrm{L}$ (panel $C$ ) are depicted for the postinjection intervals indicated on the left of each gel. The progressive and coordinated distribution of the three NFP subunits between 3 and $15 \mathrm{~d}$ is apparent.

groups may influence the charge and electrophoretic properties of the proteins (Julien and Mushynski, 1982; Kaufmann et al., 1984). Therefore, we sought evidence for posttranslational modification of NFPs by kinases or phosphatases in RGC axons by noting changes in the isoelectric points of NFPs as they were axonally transported. Two-dimensional electrophoretic analyses of optic nerve and optic tract proteins from mice that had been injected intravitreally with ${ }^{32} \mathrm{P}$-orthophosphate or ${ }^{3} \mathrm{H}$-pro- 

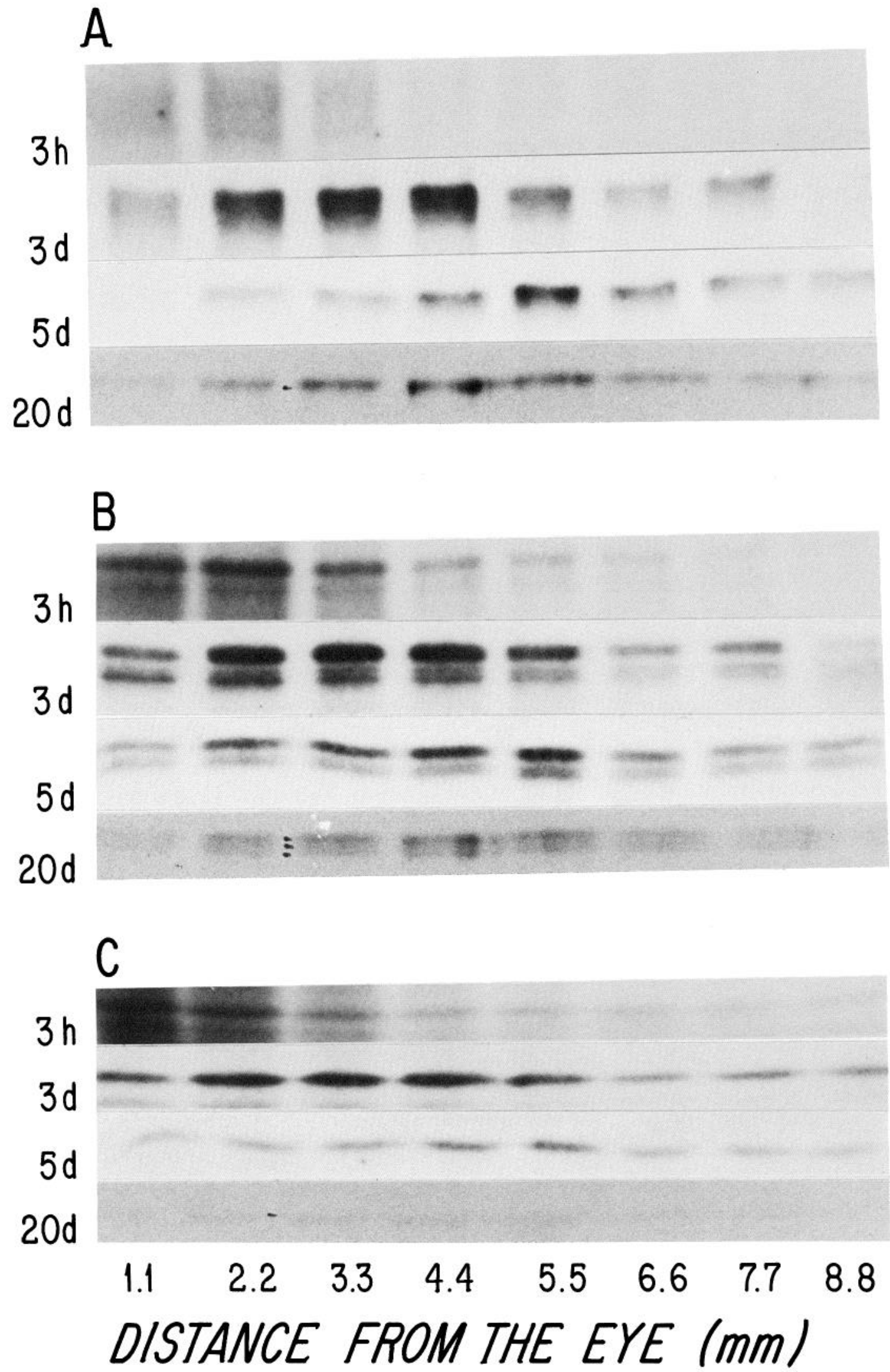

Figure 4. Distribution of radiolabeled NFPs along RGC axons after intravitreal injection of ${ }^{32} \mathrm{P}$-orthophosphate. Consecutive $1.1 \mathrm{~mm}$ segments of the optic pathways from mice injected intravitreally with ${ }^{32} \mathrm{P}$-orthophosphate were analyzed as described in Figure 3 , except that radioactivity was revealed by autoradiography. The time-dependent redistribution of $\mathrm{H}$ (panel $A$ ), $\mathrm{M}$ (panel $B$ ), and $\mathrm{L}($ panel $C$ ) at postinjection intervals of 3 $\mathrm{hr}, 3 \mathrm{~d}, 5 \mathrm{~d}$, and $20 \mathrm{~d}$ is apparent. 

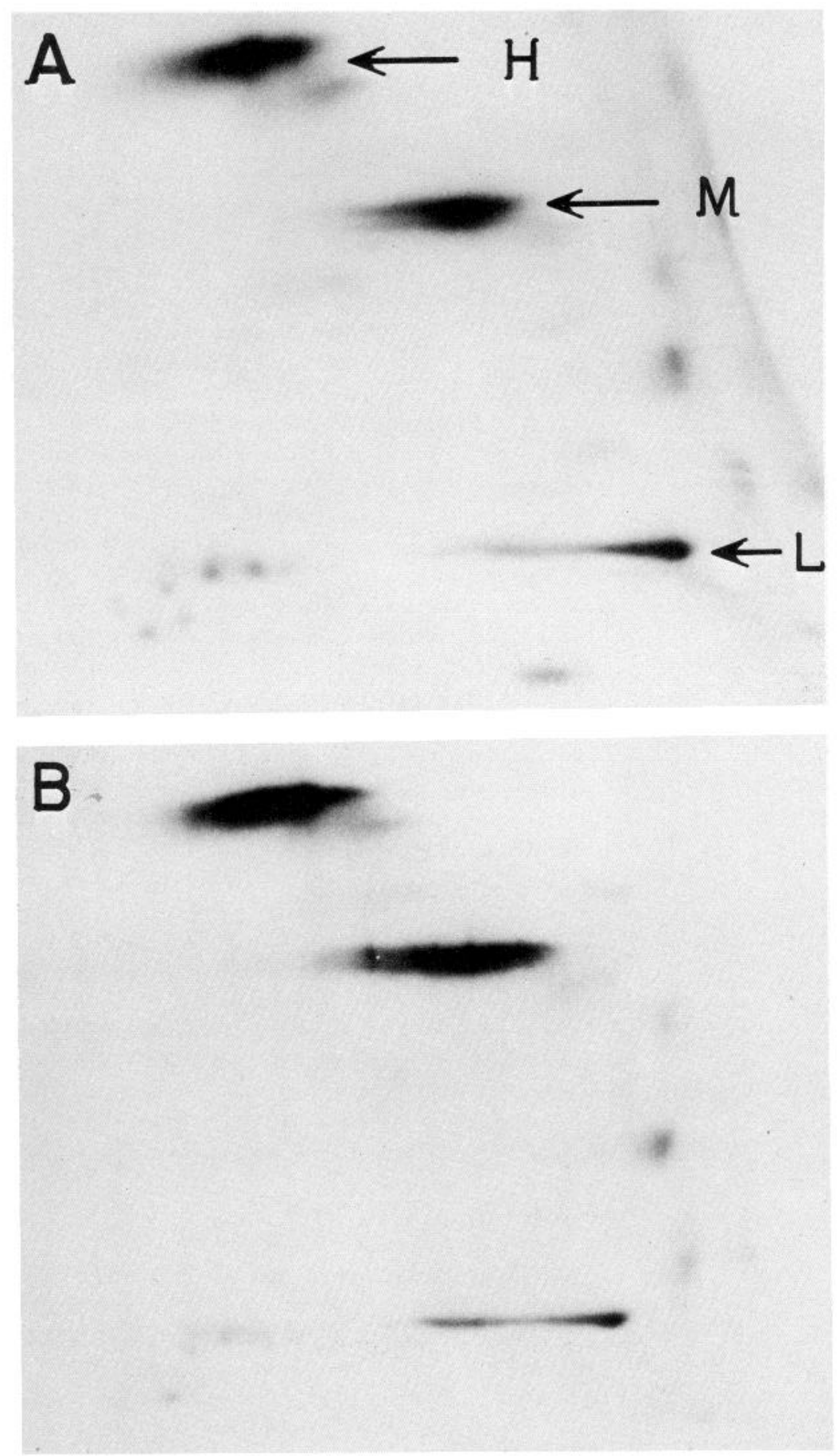

\section{$6.5|6.2| 5.8|5.6| 5.4|5.3| 4.9 \mid$} $p H$

line indicated that 2 posttranslational processes, resulting either in a postive- or negative-charge alteration, affected the individual NFP subunits. In turn, the expression of these posttranslational events depended upon 2 factors: the time interval during which NFPs resided within an axonal segment, and the location of these proteins along the length of the axon.

We first examined the effect of residence time within a given
Figure 5. Time-dependent modifications in the charge of ${ }^{32} \mathrm{P}$-labeled NFP subunits during axoplasmic transport. Mice were injected intravitreally with ${ }^{32} \mathrm{P}$-orthophosphate, and optic nerves were analyzed by 2 -dimensional electrophoresis after $1 \mathrm{~d}$ or $6 \mathrm{~d}$. The relative gel positions of $H, M$, and $L$ in optic nerve at $1 \mathrm{~d}($ panel $A$ ) and at $6 \mathrm{~d}$ (panel $B)$ are shown. axonal region on NFP modifications. ${ }^{32} \mathrm{P}$-radiolabeled $\mathrm{L}$ in optic nerve shifted $0.2 \mathrm{pH}$ units toward the basic end of gels between days 1 and 6 after injection of the isotope (compare Fig. 5, $A$, $B$ ). Careful matching of the autoradiographs of Figure 5, using Coomassie blue proteins on the dried gels as internal reference points (see Fig. 2), indicated that during the same interval, the charge of the $\mathrm{H}$ subunit became slightly more acidic $(0.2 \mathrm{pH}$ 

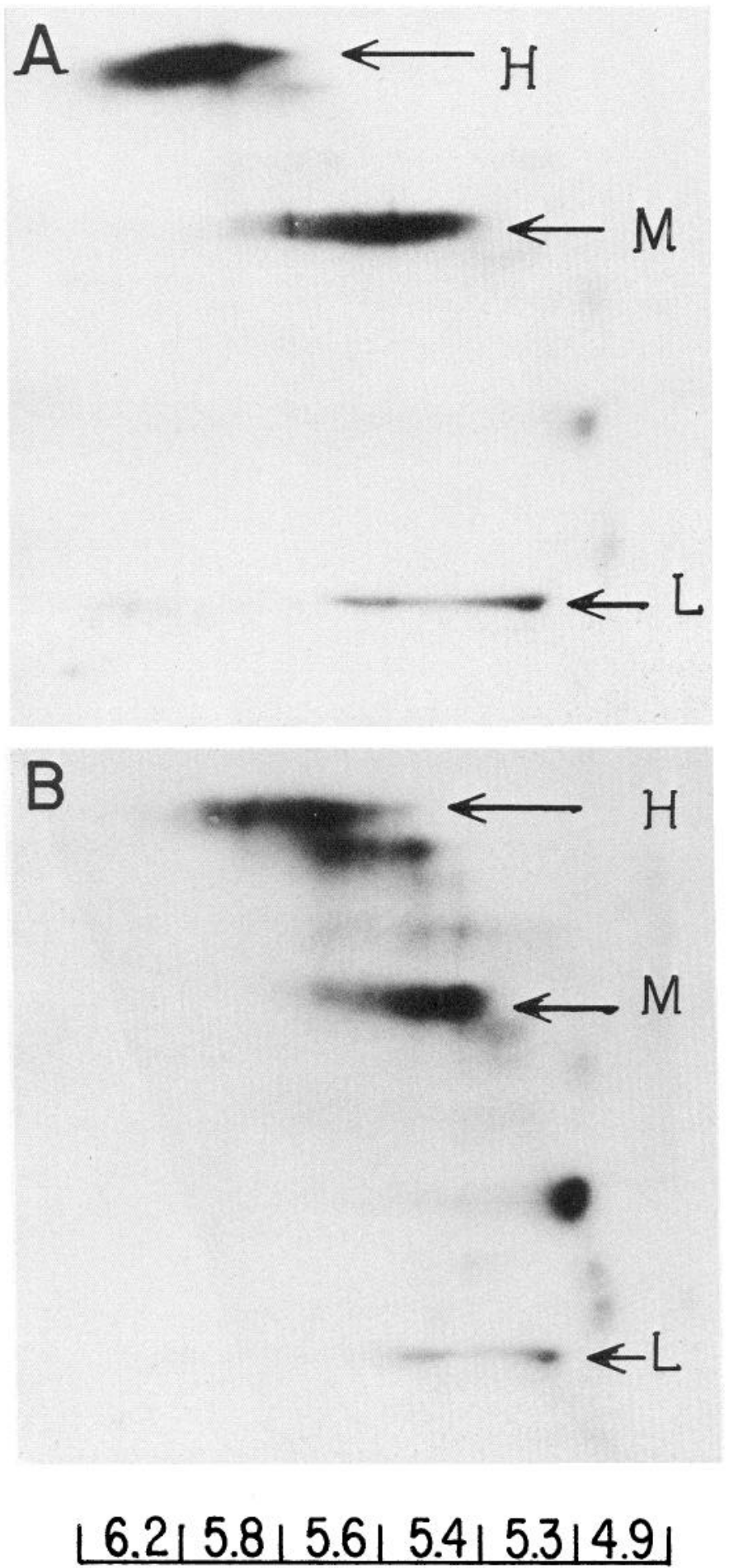

$$
p H
$$

Figure 6. Location-dependent modifications of the charge of ${ }^{32} \mathrm{P}-\mathrm{la}-$ beled NFP subunits during axoplasmic transport. Mice were injected intravitreally with ${ }^{32} \mathrm{P}$-orthophosphate and the optic nerve and optic tracts were analyzed separately by 2-dimensional SDS-PAGE after $6 \mathrm{~d}$ survival. The gel positions of $H, M$, and $L$ in the optic nerve (panel $A$ ) and in the optic tract (panel $B$ ) at $6 \mathrm{~d}$ postinjection are shown. The prominent shift in isoelectric point of $H$ is clearly seen. In $B$, a breakdown product of $\mathrm{H}$ is observed below the spot corresponding to intact $\mathrm{H}$. This additional labeled polypeptide was not reproducibly seen in repetitions of this experiment. The positions of protein markers, stained with Coomassie blue, coincided on each gel. units). The latter modification, however, showed a greater dependence on the location of labeled $\mathrm{H}$ along the length of the axon. For example, comparisons of $\mathrm{H}$ at proximal axonal levels (optic nerve) with $\mathrm{H}$ at distal axonal levels (optic tract) in mice after the same $6 \mathrm{~d}$ postinjection interval demonstrated an acidic shift of $0.3 \mathrm{pH}$ units for this subunit in distant axonal sites (compare Fig. 6, $A, B$ ). A shift in the $\mathrm{p} I$ of $\mathrm{M}$ in optic nerve, as compared with optic tract, at $6 \mathrm{~d}$ after injection was qualitatively similar to, but less striking than, that of $\mathrm{H}$ (Fig. 6, $A, B$ ). By contrast, little difference in the charge of $\mathrm{L}$ was observed at these 2 axonal levels. Each of the foregoing modifications was observed in multiple replications of these experiments.

To further verify that these charge modifications were in vivo events, we investigated the electrophoretic behavior of NFPs labeled with ${ }^{3} \mathrm{H}$-proline and isolated at various time points after axoplasmic transport. Charge alterations similar to those of ${ }^{32} \mathrm{P}-$ labeled NFPs were observed. Two-dimensional electrophoretograms of optic nerves and optic tracts were compared at 6 $\mathrm{d}$ postinjection, when the leading edge of the ${ }^{3} \mathrm{H}-\mathrm{NFP}$ wave had reached the proximal optic tract (Fig. 7). The isoelectric points of $\mathrm{H}$ and $\mathrm{M}$ in optic tract were shifted 0.4 and $0.1 \mathrm{pH}$ units, respectively, toward the acidic end of the gel, relative to their counterparts in optic nerve. The nonphosphorylated ${ }^{3} \mathrm{H}$-labeled proteins serving as standard position markers on each gel did not change position under these conditions. Consecutive 1.1 $\mathrm{mm}$ segments of the optic nerve from mice analyzed at $6 \mathrm{~d}$ postinjection demonstrated progressive degrees of the same NFP modifications (data not shown). Thus, even within the optic nerve alone, the degree to which $\mathrm{H}$ and $\mathrm{M}$ were modified was dependent on location.

Although the addition of phosphate groups to neurofilaments is one factor that may change the migration of these polypeptides in SDS polyacrylamide gels (Julien and Mushynski, 1982; Kaufman et al., 1984), no change in apparent molecular weight accompanied the modification of the 3 NFPs during axoplasmic transport. One-dimensional PAGE analyses of ${ }^{32} \mathrm{P}$ - or tritiumlabeled NFPs from optic nerve and optic tract revealed no molecular weight changes after any postinjection interval (data not shown).

\section{Alkaline phosphatase treatment of NFPs in vitro}

Experiments were carried out to confirm the effect of phosphate groups on the electrophoretic mobility of NFPs. If changes in the isoelectric points of the subunits reflected addition or removal of phosphate groups, alkaline phosphatase treatment of NFPs in vitro would be expected to mimic or reverse the modifications observed in axons in vivo. NFPs in cytoskeletal protein fractions prepared from mouse spinal cord were therefore dephosphorylated by incubation with $E$. coli alkaline phosphatase for various intervals. The effects of this treatment on the isoelectric points of the NFP subunits were then analyzed by subjecting the samples to 2-dimensional PAGE (Figs. 8 and 9). The $\mathrm{H}$ subunit appeared as a long streak, spanning the $\mathrm{pH}$ range of 6.1-5.6. Charge alterations after phosphatase treatment were visible after $10 \mathrm{~min}$ of incubation and involved a shift in the charge of $\mathrm{H}$ from a uniform streak to a more focused spot that overlapped the $\mathrm{p} I$ range of 6.3-5.9. As phosphatase digestion proceeded, the charge of $\mathrm{H}$ became progressively more basic until a stable isoelectric point of 6.6-6.5 was reached after 40 min of incubation (Figs. 8, 9). With the progression of these changes in isoelectric point, the configuration of the $\mathrm{H}$ spot became more oblique as the most basic of the heterogeneous 

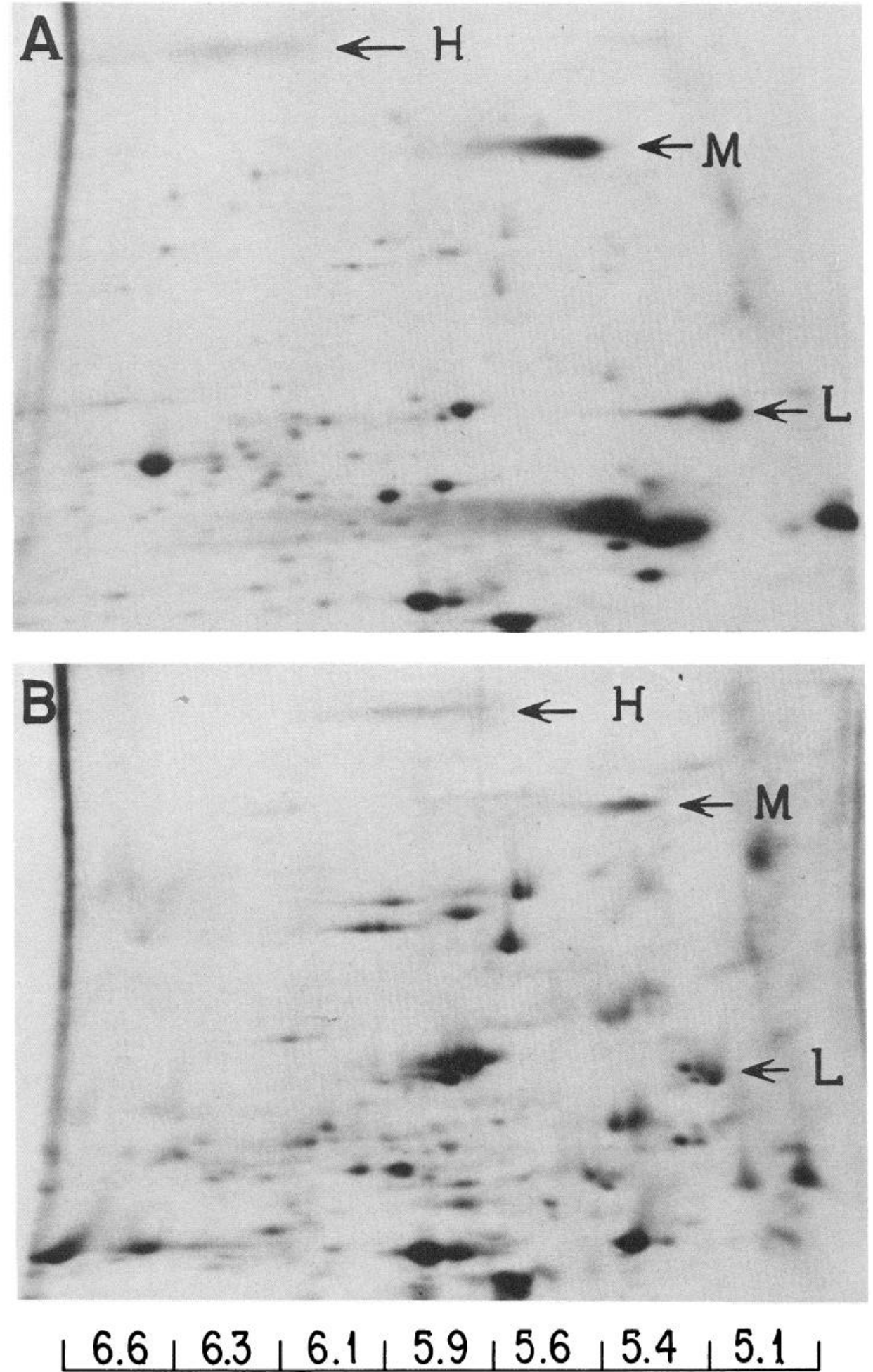

\section{pH}

forms exhibited a more rapid mobility on the gel than did acidic forms (e.g., after 10 min of incubation; Fig. $8 \mathrm{C}$ ). After extensive dephosphorylation, the entire population of $\mathrm{H}$ molecules displayed a lower apparent molecular weight, as well as a more basic $\mathrm{p} I$, compared with untreated $\mathrm{H}$. These alterations in the electrophoretic mobility of $\mathrm{H}$ were most readily apparent on
Figure 7. Modifications in the charge of ${ }^{3} \mathrm{H}$-labeled NFP subunits during axoplasmic transport. Mice were injected intravitreally with ${ }^{3} \mathrm{H}$-proline and the optic nerve and optic tract were analyzed separately by 2 -dimensional SDSPAGE after $6 \mathrm{~d}$. A shift in the isoelectric point of $H$ and $M$ toward a more acidic $\mathrm{pH}$ and a slight shift in the isoelectric point of $L$ toward a more basic $\mathrm{pH}$ are seen. By contrast, the relative positions of most other radiolabeled proteins on these gels are the same, confirming that the shifts in isoelectric points of NFP subunits are not due to variability of the gels. silver-stained gels from early and late time points (Fig. 9). In comparision with the $\mathrm{H}$ subunit, the $\mathrm{M}$ and $\mathrm{L}$ subunits displayed smaller shifts toward a slightly more basic $\mathrm{p} I$ (Fig. 8) after alkaline phosphatase digestion.

The relationship between changes in electrophoretic mobility and loss of phosphate groups was investigated using ${ }^{32} \mathrm{P}$-labeled 


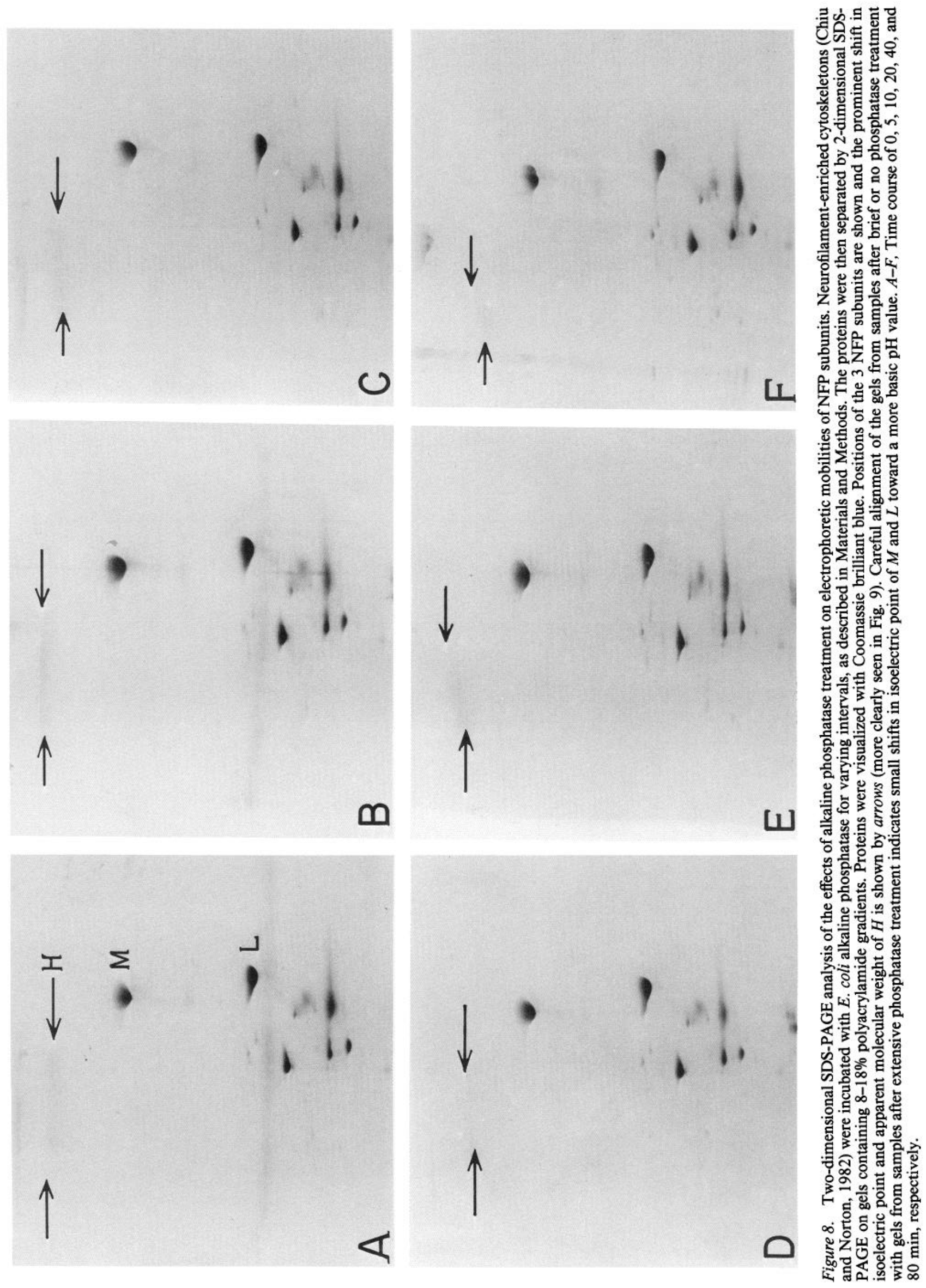



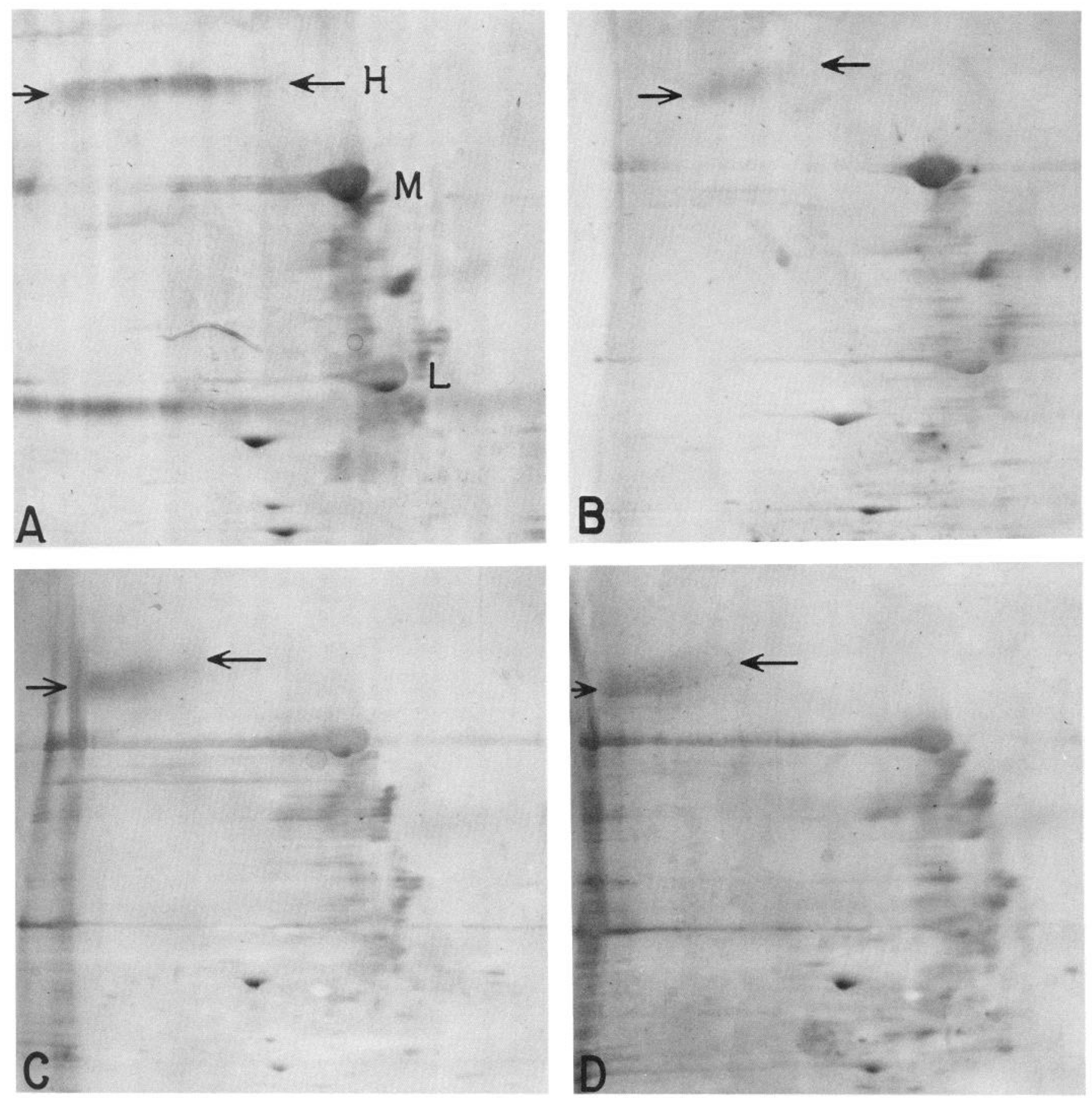

Figure 9. Two-dimensional SDS-PAGE analysis of phosphatase-treated NFP subunits. The changes in electrophoretic mobility of $H$ indicated in Figure 8 were better appreciated after the proteins on the same gels were visualized by silver staining. Changes in the isolectric point and shifts in mobility in the molecular weight dimension of the gels are indicated by the position of the arrows on each side of the spot corresponding to $\mathrm{H}$. $A-$ $D, 0,20,40$, and $80 \mathrm{~min}$ of alkaline phosphatase digestion, respectively.

neurofilaments. NFPs radiolabeled in vivo by intravitreal injection ${ }^{32} \mathrm{P}$-phosphate were subjected to alkaline phosphatase digestion in vitro under the same conditions employed in the experiments described above. One-dimensional gel analyses confirmed that the time course of electrophoretic mobility changes was the same as that observed for spinal cord NFPs. During the first 20 min of incubation, the percentage of the total NFP-associated ${ }^{32} \mathrm{P}$ released from these polypeptides was $39 \pm 9 \%, 28 \pm 7 \%$, and $2 \pm 2 \%(n=3)$ for the $\mathrm{H}, \mathrm{M}$, and L subunits, respectively. An additional $5-10 \%$ of the total ${ }^{32} \mathrm{P}$ was released from each subunit after $3 \mathrm{hr}$ of digestion. Maximum alteration of NFP mobility on gels (Figs. 8 and 9) was therefore associated with loss of less than half of the initially incorporated phosphate groups. Control studies with ${ }^{3} \mathrm{H}$-labeled NFPs indicated that the release of ${ }^{32} \mathrm{P}$ was not due to NFP proteolysis.

\section{Discussion}

Our results demonstrate that NFPs are constituents of a limited class of proteins that are extensively phosphorylated in vivo and are exported by axoplasmic transport. The 200,140 , and 70 
$\mathrm{kDa}$ polypeptides that incorporated high levels of ${ }^{32} \mathrm{P}$-inorganic phosphate were identified as NFPs by various criteria, including their molecular weights and isoelectric points on SDS gels, Triton-insolubility (Nixon and Lewis, 1986), and immunoprecipitation by specific antibodies to each NFP subunit (Nixon and Lewis, 1986). While displaying the characteristic chemical properties of NFPs, these ${ }^{32} \mathrm{P}$-labeled proteins exhibited a different pattern of axonal transport than NFPs labeled with ${ }^{3} \mathrm{H}$-prolinc, which moved in the Group V (SCa) phase of axoplasmic transport (Black and I asek, 1980; Nixon et al., 1982). The leading edge of the ${ }^{32} \mathrm{P}$-labeled NFP wave moved at a rate of at least $1.8 \mathrm{~mm} / \mathrm{d}$. The observation that ${ }^{32} \mathrm{P}$-labeled NFPs were still present along the entire axonal length at $20 \mathrm{~d}$ postinjection, however, suggests that some ${ }^{32} \mathrm{P}$-labeled NFPs advanced at the slower, Group $\mathrm{V}$ rate. The absence of measurable ${ }^{3} \mathbf{H}$-proline label, associated with the faster-moving fraction of ${ }^{32} \mathrm{P}$-labeled NFPs in comparision studies using the 2 isotopes, weighs against the latter proteins' being a special class of rapidly transported ${ }^{32} \mathrm{P}$ NFPs. These results, therefore, are consistent with the possibility that intravitreally injected ${ }^{32} \mathrm{P}$-inorganic phosphate labels a molecule that is transported more rapidly than are NFPs along axons. ATP and other high-energy phosphates are present along axons (Davies, 1978; Leone and Ochs, 1978) and, although abundant quantities are generated locally, a fraction of these compounds may also be contained within mitochondria, synaptic vesicles, and other organelles (Davies, 1978). The latter are exported from RGC perikarya and move at faster rates than do NFPs. If these proteins incorporate ${ }^{32} \mathrm{P}$-label, the apparent movement of ${ }^{32} \mathrm{P}$-labeled NFPs at rates faster than that of Group $\mathrm{V}$ proteins would not be expected to accurately reflect transport of the neurofilament polypeptide backbone.

The most striking in vivo modifications of NFPs once they entered axons involved a progressive shift in the isoelectric point of $\mathrm{H}$ from 6.2 to $5.6 \mathrm{pH}$ units. This charge shift reflected the addition of phosphate groups to the protein, since treating $\mathrm{H}$ with alkaline phosphatase in vitro induced comparable shifts in subunit charge in the reverse direction, i.e., toward more basic $\mathrm{pH}$ values, concomitant with release of ${ }^{32} \mathrm{P}$ radioactivity from the protein. Although the in vivo modification process greatly altered the charge of $\mathrm{H}$, the number of phosphates added to this subunit along optic axons may be smaller than the number added in proximal (intraretinal) axons or cell bodies (Nixon et al., 1986). This is suggested by the finding that isoelectric point modifications of $\mathbf{H}$ along axons could be reversed with alkaline phosphatase by removing fewer than $40 \%$ of the ${ }^{32} \mathrm{P}$-phosphates initially incorporated into the subunit. Decreases in the electrophoretic mobility of NFPs in the SDS dircction accompany the early stages of phosphorylation in very proximal axonal levels (Nixon et al., 1986), and opposite effects on mobility were seen in the present study using extensive alkaline phosphatase digestions. No modifications altering migration in the SDS direction, however, were observed during axonal transport along the optic nerve and optic tract. Since the anomalous migration of NFPs in the SDS direction may reflect not only modification by phosphate but other unusual charge properties of the polypeptides (Geisler et al., 1985b), the rates of migration during PAGE do not appear to be a strictly quantitative index of changes in the phosphate content of NFPs.

The conclusion that $\mathrm{H}$ continues to be phosphorylated during axoplasmic transport is supported by previous immunocytochemical studies demonstrating that monoclonal antibodies to nonphosphorylated epitopes on $\mathrm{H}$ recognize neurofilaments in cell bodies and proximal axons, while antibodies to certain phosphorylated epitopes react with long fibers, including terminal axons (Sternberger and Sternberger, 1983). Furthermore, reactivity with antibodies against phosphorylated epitopes on $\mathrm{H}$ is absent or weak in RGC perikarya and very proximal (intraretinal) levels of RGC axons, but increases greatly at axonal levels near the optic disc and in the optic nerve (Dräger and Hofbauer, 1984; Dräger ct al., 1984).

The possibility that the number of phosphates added to $\mathrm{H}$ along extraretinal portions of RGC axons is small does not diminish the potential importance of this modification in regulating dynamic functions of neurofilaments along axons, since total phosphate content may be a less critical variable than the site of phosphorylation. Our results indicate that phosphate is added to new sites on $\mathrm{H}$ and that adding a relatively small number of phosphates to the $\mathrm{H}$ subunit of neurofilaments entering distal levels of RGC axons results in a substantially modified charge of this polypeptide.

The shift in the isoelectric point toward a more negative charge during axoplasmic transport suggests that the $\mathrm{L}$ subunit undergoes a net dephosphorylation after it enters axons. Despite the relatively low phosphate content of NFP-L in axons (Jones and Williams, 1982; Julien and Mushynski, 1982), an additional shift in isoelectric point in the basic direction could be induced by treating $\mathrm{L}$ with alkaline phosphatase in vitro. The conclusion that the charge modifications in vivo represented loss of phosphate groups from $\mathrm{L}$ is also supported by recent observations that more than half of the ${ }^{32} \mathrm{P}$-labeled phosphate groups initially incorporated into $\mathrm{L}$ from an intravitreal injection of ${ }^{32} \mathrm{P}$-inorganic phosphate are removed within several days after the radiolabeled neurofilaments are transported into RGC axons (Nixon and Lewis, 1986).

Although $\mathrm{M}$ displays a high phosphate content (Iones and Williams, 1982; Julien and Mushynski, 1982), changes in its phosphorylation state were difficult to estimate because the shifts in isoelectric point that accompanied removal of phosphate groups from this subunit in vitro were relatively small. Nevertheless, the small charge shift toward a more acidic $\mathrm{pH}$ after $\mathrm{M}$ entered axons and reversal of this shift by treating isolated neurofilaments with alkaline phosphatase in vitro suggested a net addition of phosphate groups to this subunit along axons in vivo. As was previously discussed in the case of $\mathrm{H}$, however, the net increase in phosphate groups to $\mathrm{M}$ along axons at the optic nerve level appears to be smaller than the number added at more proximal sites. Removing less than $30 \%$ of the phosphate groups on $\mathrm{M}$ with alkaline phosphatase had a small effect on its charge, but also altered its migration on SDS gels to a position corresponding to a molecular weight $(139 \mathrm{kDa})$ similar to that of the newly synthesized unphosphorylated form of $\mathrm{M}$ detected in $\mathrm{RGC}$ perikarya (Nixon et al., 1986), and to the M subunit isolated from a cell-free translation mixture containing wheat germ factors and mRNA from rat spinal cord (Strocchi et al., 1982). After entering axons at the optic nerve level, however, $M$ exists predominantly as a $145 \mathrm{kDa}$ protein and exhibits no further increase in apparent molecular weight on SDS gels as it is transported. The more extensive phosphate addition in proximal axons is also indicated by recent studies of newly synthesized NFPs in cultures of chicken spinal cord neurons (Bennett and DiLullo, 1985) and rat sympathetic neurons (Black et al., 1986). Although the foregoing results suggest a net increase in the phosphorylation state of $M$, they do not address the question of whether or not some phosphate groups are lost as others are 
added in axons. Kinetic studies of ${ }^{32} \mathrm{P}$-labeled NFPs, however, have indicated that phosphate groups on $\mathbf{M}$ are turned over along axons and that the steady-state phosphate content of $\mathrm{M}$ reflects a dynamic balance of phosphorylation and dephosphorylation (Nixon and Lewis, 1986; Nixon et al., 1986).

The posttranslational modifications of NFP subunits after they enter axons of the optic nerve level represent intermediate steps in NFP processing. Recent observations (Nixon et al., 1986; R. A. Nixon, S. E. Lewis, C. A. Marotta, and D. Dahl, unpublished observations) suggest that these phosphorylation steps are preceded by the addition of many phosphate groups in very proximal (intraretinal) regions of RGC axons. It is also possible that NFP processing events occur within axons beyond the $6 \mathrm{~d}$ postinjection time interval used in this study. For example, axonally transported NFPs in RGC axons are incorporated into a stationary cytoskeleton along axons, which persists long after the moving wave of neurofilaments has been eliminated in axon terminals (Nixon, 1986; Nixon and Logvinenko, 1986). Since stationary NFPs represent a significant proportion of the total axonal NFP pool, late modifications of this population could significantly influence the content of phosphate groups on NFP subunits measured chemically. The phosphate content of the total NFP pool in the steady state is, therefore, expected to reflect the concerted activities of early, intermediate, and late posttranslational events.

In many cell systems, phosphorylation alters the ability of cytoskeletal proteins to bind to one another or to other proteins (Jameson et al., 1980; Jameson and Caplow, 1981; Nishida et al., 1981; Huttner et al., 1983; Murthy and Flavin, 1983; Selden and Pollard, 1983; Lu et al., 1985). The ongoing modification of NFP subunits suggests that phosphorylation and dephosphorylation events could regulate similar dynamic properties of neurofilaments within axons. Neurofilament proteins contain binding sites for various protein components of the cytoskeleton, including microtubule-associated proteins (Leterrier et al., 1981; Heimann et al., 1985) and possibly fodrin (Siman and Lynch, 1985), both of which are also phosphorylated (Theurkauf and Vallee, 1983; Goodman et al., 1984; Nixon, 1986). It has recently been shown that an extensive reorganization of NFPs takes place during axoplasmic transport in RGC neurons. As newly synthesized neurofilaments enter optic axons, a substantial proportion is deposited along axons into a nonuniform stationary cytoskeletal network (Nixon and Logvinenko, 1986; Nixon, 1987) that is composed of various cytoskeletal elements (R. A. Nixon, unpublished observations). Since the transition of neurofilaments from a moving to a stationary phase is likely to involve dynamic interactions with other cytoskeletal proteins, it can be suggested that the phosphorylation and dephosphorylation of neurofilament proteins during axoplasmic transport serves to regulate aspects of this reorganizational process.

\section{References}

Bennett, G. S., and C. DiLullo (1985) Slow posttranslational modification of a neurofilament protein. J. Cell Biol. 100: 1799-1804.

Black, M. M., and R. J. Lasek (1980) Slow components of axonal transport: Two cytoskeletal networks. J. Cell Biol. 86: 616-623.

Black, M. M., P. Keyser, and E. Sobel (1986) Interval between the synthesis and assembly of cytoskeletal proteins in cultured neurons. J. Neurosci. 6: 1004-1012.

Brown, B. A., R. A. Nixon, P. Strocchi, and C. A. Marotta (1981) Characterization and comparison of neurofilament proteins from rat and mouse CNS. J. Neurochem. 36: 143-153.

Brown, B. A., R. A. Nixon, and C. A. Marotta (1982) Posttranslational processing of $\alpha$-tubulin during axoplasmic transport in CNS axons. J. Cell Biol. 94: 159-164.

Carden, M. J., W. W. Schlaepfer, and V. M.-Y. Lee (1985) The structure, biochemical properties, and immunogenicity of neurofilament peripheral regions are determined by phosphorylation state. J. Biol. Chem. 260: 9805-9817.

Chiu, F.-C., and W. T. Norton (1982) Bulk preparation of CNS cytoskeleton and the separation of individual neurofilament proteins by gel filtration: Dye-binding characteritics and amino acid compositions. J. Neurochem. 39: 1252-1260.

Cork, L. C., N. H. Sternberger, L. A. Sternberger, M. F. Casanova, R. G. Struble, and D. L. Price (1986) Phosphorylated neurofilament antigens in neurofibrillary tangles in Alzheimer's disease. J. Neuropathol. Exp. Neurol. 45: 56-64.

Davies, L. P. (1978) ATP in cholinergic nerves: Evidence for the axonal transport of a stable pool. Exp. Brain Res. 33: 149-157.

Dräger, U. C., and A. Hofbauer (1984) Antibodies to heavy neurofilament subunit detect a subpopulation of damaged ganglion cells in retina. Nature 309: 624-626.

Dräger, U. C., D. L. Edwards, and C. J. Barnstable (1984) Antibodies against filamentous components in discrete cell types of the mouse retina. J. Neurosci. 4: 2025-2042.

Fuchs, E., and I. Hanukoglu (1983) Unraveling the structure of the intermediate filaments. Cell 34: 332-334.

Geisler, N., and K. Weber (1981) Self-assembly in vitro of the 68,000 molecular weight component of the mammalian neurofilament triplet proteins into intermediate-sized filaments. J. Mol. Biol. 151: 565571.

Geisler, N., E. Kaufmann, S. Fischer, U. Plessman, and K. Weber (1983) Neurofilament architecture combines structural principles of intermediate filaments with carboxy-terminal extensions increasing in size between triplet proteins. EMBO J. 2: 1295-1302.

Geisler, N., S. Fischer, J. Vandekerckhove, J. Van Damme, U. Plessman, and K. Weber (1985a) Protein-chemical characterization of $\mathrm{NF}-\mathrm{H}$, the largest mammalian neurofilament component: Intermediate filament-type sequences followed by a unique carboxy-terminal extension. EMBO J. 4: 57-63.

Geisler, N., U. Plessmann, and K. Weber (1985b) The complete amino acid sequence of the major mammalian neurofilament protein (NFL). FEBS Lett. 182: 475-478.

Goodman, S. R., I. S. Zagon, C. F. Whitefield, L. A. Casoria, S. B. Shohet, S. E. Bernstein, P. J. McLaughlin, and T. L. Laskiewicz (1984) A spectrin-like protein from mouse brain membrane: Phosphorylation of the 235,000-dalton subunit. Am. J. Physiol. 247 (Cell Physiol. 16): $\mathrm{C} 61-\mathrm{C} 73$.

Hcimann, R., M. L. Shelanski, and R. K. H. Liem (1985) Microtubuleassociated proteins bind specifically to the 70-kDa neurofilament protein. J. Biol. Chem. 260: 12160-12166.

Hirokawa, N., M. A. Glicksman, and M. B. Willard (1984) Organization of mammalian neurofilament polypeptides within the neuronal cytoskeleton. J. Cell Biol. 98: 1523-1536.

Hoffman, P. N., and R. J. Lasek (1975) The slow component of axonal transport: Identification of major structural polypeptides of the axon and their generality among mammalian neurons. J. Cell Biol. 66: 351-366.

Hoffman, P. N., J. W. Griffin, and D. L. Price (1984) Control of axonal caliber by neurofilament transport. J. Cell Biol. 99: 705-714.

Huttner, W. B., W. Schiebler, P. Greengard, and P. de Camilli (1983) Synapsin (protein I), a nerve terminal-specific phosphoprotein. III. Its association with synaptic vesicles studied in a highly purified synaptic vesicle preparation. J. Cell Biol. 96: 1374-1388.

Jameson, L., and M. Caplow (1981) Modification of microtubule steadystate dynamics by phosphorylation of the microtubule-associated proteins. Proc. Natl. Acad. Sci. USA 78: 3413-3417.

Jameson, L., T. Frey, B. Zeeberg, F. Dalldorf, and M. Caplow (1980) Inhibition of microtubule assembly by phosphorylation of microtubule-associated proteins. Biochemistry 19: 2472-2479.

Jones, J. C. R., A. E. Goldman, H.-Y. Yang, and R. D. Goldman (1985) The organizational fate of intermediate filament networks in two epithelial cell types during mitosis. J. Cell Biol. 100: 93-102.

Jones, S. M., and R. C. Williams, Jr. (1982) Phosphate content of mammalian neurofilaments. J. Biol. Chem. 257: 9902-9905.

Julien, J.-P., and W. E. Mushynski (1982) Multiple phosphorylation sites in mammalian neurofilament polypeptides. J. Biol. Chem. 257: 10467-10470. 
Julien, J.-P., G. D. Smoluk, and W. E. Mushynski (1983) Characteristics of the protein kinase activity associated with rat neurofilament preparations. Biochim. Biophys. Acta 755: 25-31.

Kaufmann, E., N. Geisler, and K. Weber (1984) SDS-PAGE strongly overestimates the molecular masses of the neurofilament proteins. FEBS Lett. 170: 81-84.

Lasek, R. J., M. M. Oblinger, and P. F. Drake (1984) Molecular biology of neuronal geometry: Expression of neurofilament genes influences axonal diameters. Cold Spring Harbor Symp. Quant. Biol. 48: 731744.

Lazarides, E. (1980) Intermediate filaments as mechanical integrators of cellular space. Nature 283: 249-256.

Leone, J., and S. Ochs (1978) Axonic block and recovery of axoplasmic transport and electrical excitability of nerve. J. Neurobiol. 9: 229245.

Leterrier, J.-F., R. K. H. Liem, and M. L. Shelanski (1981) Preferential phosphorylation of the 150,000 molecular weight component of neurofilaments by a cyclic AMP-dependent microtubule-associated protein kinase. J. Cell Biol. 90: 755-760.

Lewis, S. E., and R. A. Nixon (1985) Microheterogeneity of the 200,000 dalton neurofilament protein (NFP). 'Irans. Amer. Soc. Neurochem. 16: 245 .

Liem, R. K. H., and S. B. Hutchison (1982) Purification of individual components of the neurofilament triplet: Filament assembly from the 70,000-dalton subunit. Biochemistry 21:3221-3226.

Liem, R. K. H., S.-H. Yen, G. D. Salomon, and M. L. Shelanski (1978) Intermediate filaments in nervous tissue. J. Cell Biol. 79: 637-645.

Lu, P.-W., C.-J. Soong, and M. Tao (1985) Phosphorylation of ankyrin decreases its affinity for spectrin tetramer. J. Biol. Chem. 260: 1495814964.

Marotta, C. A. (1984) Neuronal intermediate filaments. In Handbook of Neurochemistry, vol. 7, A. Lajtha, ed., pp. 281-314, Plenum, New York.

Marotta, C. A., P. Strocchi, and J. M. Gilbert (1979) Biosynthesis of heterogeneous forms of mammalian brain tubulin subunits by multiple messenger RNAs. J. Neurochem. 33: 231-246.

Morris, J. R. and R. J. Lasek (1982) Stable polymers of the axonal cytoskeleton: The axoplasmic ghost. J. Cell Biol. 92: 192-198.

Murthy, A. S. N., and M. Flavin (1983) Microtubule assembly using the microtubule-associated protein MAP-2 prepared in defined states of phosphorylation with protein kinase and phosphatase. Eur. J. Biochem. 137: 37-46.

Nishida, E., T. Kuwaki, and H. Sakai (1981) Phosphorylation of microtubule-associated proteins (MAPs) and $\mathrm{pH}$ of the medium control interaction between MAPs and actin filaments. J. Biochem. 90:575578.

Nixon, R. A. (1983) Proteolysis of neurofilament. In Neuroflaments, C. A. Marotta, ed., pp. 117-154, U. Minnesota P., Minneapolis, MN.

Nixon, R. A. (1986) Fodrin degradation by calcium-activated neutral proteinase (CANP) in retinal ganglion cell neurons and optic glia: Preferential localization of CANP activities in neurons. J. Neurosci. 6: 1264-1271.

Nixon, R. A. (1987) The axonal transport of cytoskeletal proteins: A reappraisal. In Axonal Transport, R. S. Smith and M. A. Bisby, eds., Liss, New York (in press).

Nixon, R. A., and S. E. Lewis (1986) Differential rates of phosphate turnover on neurofilament subunits in retinal ganglion cell neurons in vivo. J. Biol. Chem. 261: 16298-16301.

Nixon, R. A., and K. B. Logvinenko (1986) Multiple fates of newly synthesized neurofilament proteins: Evidence for a stationary neurofilament network distributed nonuniformly along axons of retinal ganglion cell neurons. J. Cell Biol. 102: 647-659.
Nixon, R. A., B. A. Brown, and C. A. Marotta (1982) Posttranslational modification of a neurofilament protein during axoplasmic transport: Implications for regional specialization of CNS axons. J. Cell Biol. 94: $150-158$

Nixon, R. A., B. A. Brown, and C. A. Marotta (1983) Limited proteolytic modification of a neurofilament protein involves a proteinase activated by endogenous levels of calcium. Brain Res. 275: 384-388.

Nixon, R. A., S. E. Lewis, C. A. Marotta, and D. Dahl (1986) Early posttranslational modification of neurofilament proteins in retinal ganglion cell neurons in vivo (abstract). J. Cell Biol. 103: 421a.

O'Connor, C. M., D. L. Gard, and E. Lazarides (1981) Phosphorylation of intermediate filament proteins by cAMP-dependent protein kinases. Cell 23: 135-143.

Pant, H. C., P. E. Gallant, and H. Gainer (1986) Characterization of a cyclic nucleotide- and calcium-dependent neurofilament protein kinase activity in axoplasm from the squid giant axon. J. Biol. Chem. 261: 2968-2977.

Selden, S. C., and T. D. Pollard (1983) Phosphorylation of microtubule-associated proteins regulates their interaction with actin filaments. J. Biol. Chem. 258: 7064-7071.

Sharp, G. A., G. Shaw, and K. Weber (1982) Immunoelectromicroscopical localization of the three neurofilament triplet proteins along neurofilaments of cultured dorsal root ganglion neurones. Exp. Cell Res. 137: 403-413.

Shecket, G., and R. J. Lasek (1982) Neurofilament protein phosphorylation. Species generality and reaction characteristics. J. Biol. Chem. 257: 4788-4795.

Shelanski, M. L., and R. K. H. Liem (1979) Neurofilaments. J. Neurochem. 33: 5-13.

Siman, R., and G. Lynch (1985) Fodrin: Skeletal protein cross-linker in rat brain subcellular fractions. Neurosci. Abstr. 11: 775.

Steinert, P. M., M. L. Wantz, and W. W. Idlcr (1982) $O$-phosphoscrinc content of intermediate filament subunits. Biochemistry 21:177-183.

Steinert, P. M., C. R. Jonathan, R. Jones, and R. D. Goldman (1984) Intermediate filaments. J. Cell Biol. 99: 22s-27s.

Steinert, P. M., A. C. Steven, and D. R. Roop (1985) The molecular biology of intermediate filament. Cell 42: 411-419.

Sternberger, L. A., and N. H. Sternberger (1983) Monoclonal antibodies distinguish phosphorylated and nonphosphorylated forms of neurofilaments in situ. Proc. Natl. Acad. Sci. USA 80: 6126-6130.

Strocchi, P., D. Dahl, and J. M. Gilbert (1982) Studies on the biosynthesis of intermediate filament proteins in the rat CNS. J. Neurochem. 39: 1132-1141.

Theurkauf, W. E., and R. B. Vallee (1983) Extensive cAMP-dependent and cAMP-independent phosphorylation of microtubule-associated protcin 2. J. Biol. Chcm. 258: 7883-7886.

Troncoso, J. C., N. H. Sternberger, L. A. Sternberger, P. N. Hoffman, and D. L. Price (1986) Immunocytochemical studies of neurofilament antigens in the neurofibrillary pathology induced by aluminum. Brain Res. 364: 295-300.

Weber, K., G. Shaw, M. Osborn, E. Debus, and W. Geisler (1983) Neurofilaments, a subclass of intermediate filaments: Structure and expression. Cold Spring Harbor Symp. Quant. Biol. 48: 717-729.

Willard, M. (1983) Neurofilaments and axonal transport. In Neurofilaments, C. A. Marotta, ed., pp. 86-116, U. Minnesota P., Minneapolis, $\mathrm{MN}$.

Willard, M., and C. Simon (1981) Antibody decoration of neurofilaments. J. Cell Biol. 89: 198-205.

Wong, J., S. F. Hutchison, and R. K. H. Liem (1984) An isoelectric variant of the 150,000 -dalton neurofilament polypeptide. Evidence that phosphorylation state affects its association with the filament. $\mathrm{J}$. Biol. Chem. 259: 10867-10874. 